\title{
Iurismo no Brasil: Imagem e Comunicação
}

\author{
Mário Jorge Pires
}

RESUMO: Uma política vaga no que concerne às diretrizes do Turismo no Brasil e enfoques nitidamente equivocados sobre a maneira de vender o produto turístico no Exterior são os responsáveis pelos números absolutamente inexpressivos do Turismo brasileiro. Este artigo trata dos perigos e falácias de dar ênfase quase que exclusiva ao aspecto natureza, de atribuir à imprensa a culpa pela nossa má imagem e das abordagens puramente econômicas, que não alcançam o fenômeno na sua complexidade e sutileza.

PALAVRAS-CHAVE: Produto turístico; comunicação; política de turismo; Brasil.

ABSTRACT: The vaguetouristic politics and the mistaken focus are the way how the Brazilian touristic product has been sold abroad. These elements are fully responsible for the inexpressive statistical figures of the tourism business. This articlefocuses on the misunderstandings and menaces of the three aspects that haven't been able to analyze the subject in its all complexities and subleties: first the excessive emphasis on the Natural Resources; second, the negative image of Brazil overseas is considered as a result of the media actions; last, the approaches of Tourism Activity in our country use to be purely economic.

KEI'IVOIWS: Touristic product; conmmunication; touristic politics; Brazil.

1. Professor do curso de Turismo da Escola de Comunicações e Artes da Universidade de São Paulo.

End. para corresp.: Escola de Comunicações e Artess - Departamento de Relações Públicas, Propaganda e Turismo. Av. Prof. Lúcio Martins Rodrigues, 443 - Bloco B - Cidade Universitária - 05508-900 - São Paulo - SF - Brasil. 


\section{Introduçāo}

Mesmo considerando o aspecto puramente econômico do Turismo, no que tange às possibilidades mercadológicas, a imagem das destinações insere-se no conceito geral a que todos os outros bens e serviços estão sujeitos. Destinações são "produtos" vendáveis e, portanto, capazes de criar imagens boas ou ruins, em tudo semelhantes aos produtos tangiveis (Ryan, 1994: 294).

A EMBRATUR, órgão máximo do turismo brasileiro, editou há pouco tempo as suas principais diretrizes para o fomento desta atividade, onde se incluem políticade formação e melhorqualificação demão-de-obra, increme

e utilização racional dos atrativos naturais, um destaque especial à pesca de lazer: quase nada sobre recursos culturais e uma sucessão de itens que, do ponto de vista conceitual, são bastante óbvios. Linhas gerais vagas, portanto, por isso passíveis de profusas interpretações por parte de qualquer um dos potenciaisevecutores dos tais itens arrolados.

Tal plano visa, entre outros objetivos, mudar a visão que o cstrangeiro, afeito a viagens, tem do Brasil, a qual não é nada abonadora, agravada pela veiculação de imagens que vão da miséria e violência ao "lurismo sexual". Tarefa complicada, principalmente porque o esboço de estratégia, que o plano encerra, ainda mantém arcaicos paradigmas. Um dos principais é o de não maximizar todos os recursos turísticos, partindo-se do pressuposto de que o forte é a natureza: os outros recursos poderão ser relegados a um plano inferior. Ocorre porém que, tradicionalmente, o turismo sempre recebeu uma atenção exígua por parte do Governo Federal e até mesmo aqueles itens considerados prioritários são de dificílima implantação, que dirá daqueles que ficaram em segundo lugar no planejamento.

\section{Nossa Civilizaçāo é tāo Medíocre Assim?}

Estratégia de alavancagem envolve uma verdadeira campanha, em que os recursos turísticos se compõem de tal forma que o resultado final é muito mais do que a simples soma de todos. Assim, se o patrimônio histórico e cultural recebesse o mesmo tratamento que é dado à natureza, a imagem do Brasil começaria a se modificar. Num primeiro momento, os efeitos seriam mais imediatos na ruptura da concepção de que se trata de um povo puramente fisiológico, onde o sol, floresta praia, corpo e sexo representam o lado usufruível. Esta idéia, facilmente constatável nacabeça do europeu (principalmente, porém nãoexclusivamente), representa oÉden dessacralizado da modernidade, despojado de pureza e ingenuidade, uma vez que ta perfeição não cabe mais na categoria mental do homem amargurado e descrente do séculoXX(Machado Junior, 1995: 124-25).

Poder-se-á pagar bem caro o engano de achar que o diferencial brasileiro fundamenta-se exclusivamente na exuberância dos recursos naturais e, pior, na beleza das mulheres. Safáris de mulheres não interessa (e isso a EMBRATUR deixou bem claro). Um outro tipo, que substitui as armas de fogo por câmeras fotográficas, poderia até ser interessante, porém estamos longe de ser os mellores do mundo nessa modalidade de turismo. Nesıc ponto, os planejadoresdeveriam prestar mais atenção à quantidade brutal de concorrentes que se possui em todos os continentes e, 1 do que isso, aos números verdadeiramente insignificantes de luristas estrangeiros/ ano no país e de visitantes nos parques nacionais. Então, ao invés de se lançar toda a culpa na má divulgaçãoe.eculada noExterior ou, mais recentemente, nos aumentos da tarifase preços em geral a partir do Plano Real, que tornaram o Brasil um pais caro, deveria se ter a humildade de se reconhecer que o atual enfoque da política de turismo ć viciado e defeituoso.

Queremos vender savanas, as "savanas brasileiras"? Isso o norte-americano e o europeu comum, os que são sensiveis a este tipo de atrativo, encontram em outros lugares, por um preço bem mais acessível. Ao se concentrar todos os esforços nessa tônica, mais uma vez se acaba por voltar ao "terceiromundismo", na antiga visão: o país que oferecia matćrias-primas baratas às nações economicamente desenvolvidas, em turismo, venderá a natureza, possuidor que é de uma civilização medíocre e, por isso, destituida de atrativos. É isso o que se quer?

Disso resulta que algumas lições amargas tem-se que aprender. A primeira e, talvcz, a mais visivel de todas é que oferecer simplesmente o atrativo natureza não funciona. O que já foi feito no passado mostra este aspecto com clareza. Dizer que o Brasil tornou-se um país caro - e dai o desastroso descmpenho em termos de fluxo internacional - é apenas mais uma forma de escamotear a dolorosa realidade que se reluta em querer ver: nós não temos orgulho da nossa civilização, de tudo o que construímos, do nosso legado cultural. Isso nos faz débeis, isso nos faz subpovo aos olhos internacionais.

Será o Brasil o único a ter miséria, violência urbana (e rural) e jornais que divulgam tudo isso? Basta ser medianamente informadopara constatar as inúmeras destinações turisticas internacionais que, não obstante possuirem problemas semellhantes, seus números são bem outros. O exemplo mais flagrante é a vizinha Argentina.

Considerada uma civilização de peso na América do Sul, orgulhosa de sua cultura e de suas realizações - mesmo tendo perdido a Guerra das Malvinas -, a Argent ina vem demonst rando um desempenho surpreendente no setor de turismo nos últimos anos. De 2.727.987 luristas em 1990, encerrou o ano de $1995 \mathrm{com}$ 4.100 .956 turistas. Nessc periodo, esse crescimento manteve-se sempre ascendente na sua totalidade, mas o que chama a atenção são os números referentes à entrada de norte-americanos, que foi de 171 ,4\%. Entre 1994-1995, a variação, tendo como ponto de origem os Estados Unidos, foi de $14,4 \%$, indice bem superior ao do registrado pelo turista tradicional que visita a Argentina, ou seja, os uruguaios, que ficaram com apenas 2,8\% (Secrelaría de Turismo de la Nación). Não obstante representarem os unuguaios mais de um quarto do total de turistas (1.296.127), não se pode desprezar a evolução geral do turismo neste país e, principalmente, o desempenho em atrair turistas de países desenvolvidos, afeitos à qualidade e possuidores de amplo leque de opções de viagem (Secretaría de Turismo, 1995). 


\section{O Óbvio, o que Todo Mundo Diz}

Teml-se de reconhecer que ć realmente tentador atribuir aosaspectos puramente econômicos o ridículo desempenho do turismo brasileiro. E o que subjaz esses aspectos todos já sabem: a falta de prioridade política no país onde tudo ć prioritário. Com isso, chega-se a um aparente impasse, afinal ć uma atividade que, como qualquer outra, exige investimentos pesados e politica intensiva. Resta saber se o governo está, presentemente, disposto a tirar a atividade de sua atual condição marginal. No meu entender, não.

A razão encontra-se nlas páginas dos principais jornais diários: reformas que não acontecem, voracidade do governo, temeroso de mever em setores que lihe rendem boa taxação de impostos, fraqueza do governo com relação a grupos organizados que se beneficiam da inoperância, daí a própria dificuldade em legislar no sentido de captar novos recursos privados para a atividade turística.

Embora contundente, a descrição acima pode ser revertida a médio prazo e a história tem demonstrado que, não obstantc os mais desalcntados diagnósticos, a capacidade de determinados gnupos sociais de superar problemas surpreende atć mesmo os estudiosos mais otimistas.

Partindo-se do princípio de que haja a decantada vontade política para as tão necessárias mudanças, resta saber se os sctores envolvidos com o Turismo compreenderão o caráter holístico da atividade. Qualquer publicitário encarregado de uma campanha para um produto de consumo sabe que os aspectos mais banais, como público-alvo, preço, difcrencial do produto, disıribuição, qualidade, representam apenas uma parte a ser considerada, pois aliados a estes existem out ros, mais sutis, tais como a imagem do consumidor sobre a empresa e o produto. É por esta razão que muitas empresas gastam milhõcs patrocinando cventos culturais e esportivos. Tudo na tentativa de agregar valor à imagem da empresa ou produto.

Se cada produto comum foi criado com o intuito de satisfazer algum tipo de necessidade, e dai o maior ou menor sucesso de cada um em função do interesse do consumidor em satisfazer uma necessidade - ainda que efêmera - imagine , então, o produ to turistico, que pretende satisfazer, mais do que qualquer outro, a necessidade do sonho.

Este aspecto tem sido tratado em diversas obras de csludiosos da árca e não obstante as inúmeras divergências entre eles, em pelo menos um aspecto pode-se dizer que há quase que unanimidade: o "sonho" tem início no momento da escolla da localidade a ser visilada e ć composto sobreludo da imagem que se tem do lugar. Assim, esta pode ser estercotipada ou não de acordo com o suporte de diversas fontes, tais como matćrias em jornais e revistas, documentários e folleteria especifica. Mas, o que mais influencia esta imagem ć o relato de amigos e parentes que já tiveram a experiência da viagem (Leagneau, 1981:9).

\section{A Imprensa como "Bode Expiatório"}

Em vista disso resulta a falácia de se creditar toda a culpa dessa desastrosa imagemà imprensa, pordivulgarinformaçõesque contribuempara "dencgrir o país".
A imprensa, na verdade, apenas põc a nu aquilo que cslá ocorrendo na sociedade. Se todos cstão prcocupados com o caos do país, coml a violência e com a corrupção, os jornais irão refletir eslas inquielações.

Poucas pessoas, mesmo aquelas envolvidas cm algum setor da atividade turística, sabenl como funciona a veiculação de informações do Brasil ao noticiário intcrnacional. Tirando os acontecimentos que interessam de perto aos diversos países, ou aqueles que podem resultar cm uma crisc internacional, raramente os correspondentes cstrangciros correm atrás de notícias do nosso cotidiano (não teriam o por quê). Então, as nolícias do trivial são collidas dos próprios jornais brasilciros. Este ć um procedimento comum que abrange tanto os correspondentes estrangeiros no Brasil como os jornalistas brasileiros cm diversos países.

Deivando de lado os países onde há interferência do governo na imprensa, para se ficar apenas no mundo livre, comprecnde-se o por que de muitos roubos e atć mesmo assaltos, que são comuns cm lugares de grande destinação turística em vários países da Europa, raramente chegam atć nós. Com cerıcza não ć por preguiça dos nossos correspondentes, mas pelo fato de não constarem com freqüência dos noticiários de jornais destas localidades $\mathrm{c}$ isso ocorre porque aquela sociedade está com outros tipos de preocupações c cslas sim aparecem no noticiário, e irão certamente, compor o "press rclease" dos nossos jornalistas para passá-las ao Brasil.

Talvez o que não csteja claro ć o fato de a imprensa não estar nem alćm nem aquém da socicdade onde cla atua, masć partc intcgrante dela. Se na França, Espanha ou Estados Unidos - os três primciros no "ranking" mundial das destinações turísticas - a imprensa divulga poucas notícias desabonadoras sobre scus países, isso ocorre porque certamente os leitores dos jornais c os telespectadores querem ver outro lipo de informação: cles mesmos, veículos, jornalistas, leitores, lêm uma imagem positiva dos scus países, queacaba se refletindo nonoliciário como um todo, transcendendo os aspectos negativos, que tambćm cxiste.

\section{Consideraçōes Finais}

Quando se fala de imagem, portanto, há de se reconlıecer que não adianta uma simples divulgação através de una boa campanha institucional, porque o fruto será incvilavelmentcuma imagem artificial c postiça. Mudançasverdadciras sóocorrerão quando sc mudar a imagem que se tem de nós mesmos.

Para que isso ocorra, os pressupostos mais óbvios são as reformas que contribuem para uma melhoria da qualidade de vida geralda população. Outros, talvez não tão visíveis assim, incluem o incremento do civismo, hoje quase que completamente csquecido, porque estigmatizado como sinônimo de obrigação imposta pela. diladura militar, pecha comprecnsivel após décadas de opressão, porćm injusta, uma vez que o civisılı ć transcendente a qualquer idcologia de governo.

No que concerne à mudança da imagem do Brasil no Extcrior, oenfoque precisa ser radicalmentc mudado. Campanhas ufanistas vciculadas na mídia, sem alteração da realidade at ual, não passarão de um embuste, cujo fruto se voltará de maneira ainda maisviolenta contra nós mesmos. Disso resulta que um emprecndimento de tal monta 


\section{Mário Jorge Pires}

requer um trabalho de médio prazo, começando com consciência de que não se tem apenas cachoeiras, santuários ecológicos, uma costa maravilhosa e sol o ano inteiro, mas umacivilização pujante, capaz de forjar gênioscomo Aleijadinho, Mestre Athaíde e Carlos Gomes; mas um legado histórico reconhecido mundialmente, como Ouro Preto, Olinda e Missões, e tradições populares de importância impar, motivo de orgulho de qualquer povo.

Em suma, quando o brasileiro tiver melhor visão de seu país, seremos, em decorrência, melhor reconhecidos e apreciados no Exterior. Este aspecto, somado aos outros já abordados, provocarão a verdadeira revolução no lurismo nacional, colocando-o como importante agente no moderno descnvolvimento econômico, papel que já cumpre em out ros países que não colocaram o Turismo, neccssariamente, como prioridade número um. A mudança de imagem deve ocorrer de dentro para fora e, aí sim, reconhecido, poder-sc-á vender até mesmo as savanas brasileiras, pois mesmo estas terão novo apelo aos olhos do turista estrangeiro.

\section{Referências Bibliográficas}

RYAN, C. 1994. Leisure and tourism - the application of leisure concepts to tourist behavior - a proposed model. In:

SEATON, A. V. Tourism - the state of the art.

MACHADO JUNIOR, C. E. 1995. O mercado simbólico. In: Connnicação para o mercado. São Paulo.

SECRETARÍA DE TURISMO DE LA NACIÓN. 1955. Argentina.

LACiNEAU, Gérard. 1981. A sociologia da publicidacle. 